\title{
The role of $\gamma$-aminobutyric acid in aluminum stress tolerance in a woody plant, Liriodendron chinense $x$ tulipifera
}

\author{
Pengkai Wang ${ }^{1,2}$, Yini Dong ${ }^{1}$, Liming Zhu', Zhaodong Hao ${ }^{1}$, LingFeng $\mathrm{Hu}^{1}$, Xiangyang $\mathrm{Hu}^{3}$, Guibin Wang ${ }^{4}$, \\ Tielong Cheng ${ }^{5}$, Jisen Shi (10) ${ }^{1}$ and Jinhui Chen (1)
}

\begin{abstract}
The aluminum (Al) cation $\mathrm{Al}^{3+}$ in acidic soil shows severe rhizotoxicity that inhibits plant growth and development. Most woody plants adapted to acidic soils have evolved specific strategies against $\mathrm{Al}^{3+}$ toxicity, but the underlying mechanism remains elusive. The four-carbon amino acid gamma-aminobutyric acid (GABA) has been well studied in mammals as an inhibitory neurotransmitter; GABA also controls many physiological responses during environmental or biotic stress. The woody plant hybrid Liriodendron (L. chinense $\times$ tulipifera) is widely cultivated in China as a horticultural tree and provides high-quality timber; studying its adaptation to high Al stress is important for harnessing its ecological and economic potential. Here, we performed quantitative iTRAQ (isobaric tags for relative and absolute quantification) to study how protein expression is altered in hybrid Liriodendron leaves subjected to Al stress. Hybrid Liriodendron shows differential accumulation of several proteins related to cell wall biosynthesis, sugar and proline metabolism, antioxidant activity, cell autophagy, protein ubiquitination degradation, and anion transport in response to Al damage. We observed that Al stress upregulated glutamate decarboxylase (GAD) and its activity, leading to increased GABA biosynthesis. Additional GABA synergistically increased Al-induced antioxidant enzyme activity to efficiently scavenge ROS, enhanced proline biosynthesis, and upregulated the expression of MATE1/2, which subsequently promoted the efflux of citrate for chelation of $\mathrm{Al}^{3+}$. We also showed similar effects of GABA on enhanced $\mathrm{Al}^{3+}$ tolerance in Arabidopsis. Thus, our findings suggest a function of GABA signaling in enhancing hybrid Liriodendron tolerance to Al stress through promoting organic acid transport and sustaining the cellular redox and osmotic balance.
\end{abstract}

\section{Introduction}

Acidic soil occurs frequently on Earth; $60 \%$ of tropical and subtropical areas suffer from soil acidity, which severely limits crop yield. Environmental pollution and acid rain may also contribute to increased soil acidity. The rhizotoxic $\mathrm{Al}^{3+}$ ions become soluble in acidic soil with $\mathrm{pH}$ values below 5 and dramatically suppress root growth. Thus, Al toxicity has become a serious agronomic

\footnotetext{
Correspondence: Jinhui Chen (chenjh@njfu.edu.cn)

${ }^{1}$ Key Laboratory of Forest Genetics \& Biotechnology of Ministry of Education of China, Co-Innovation Center for Sustainable Forestry in Southern China, Nanjing Forestry University, Nanjing 210037, China

${ }^{2}$ Suzhou Polytechnic Institute of Agriculture, Suzhou 215008, China Full list of author information is available at the end of the article These authors contributed equally: Pengkai Wang, Yini Dong
}

problem that restricts crop yield; enhancing the resistance of crops and biofuels to $\mathrm{Al}$ will be a valuable strategy to increase their productivity ${ }^{1-3}$. The plant $\mathrm{Al}$ resistance mechanism can be divided into external exclusion or internal detoxification based on whether it occurs within or outside of the plant cell. Several mechanisms have been suggested to explain the external exclusion mode of $\mathrm{Al}$ resistance ${ }^{4}$. The most well-known strategy is the efflux mechanism of organic acid ions, including citrate, oxalate, or malate, from the root tip, which may then directly chelate external $\mathrm{Al}$ to prevent $\mathrm{Al}$ toxicity ${ }^{4-6}$. For most crop plants, such as rice and wheat, or model plants, such as Arabidopsis, $\mathrm{Al}$ toxicity can be a strong growth deterrent; however, most forest trees show a high tolerance to

\section{(c) The Author(s) 2021}

\footnotetext{
(c) Open Access This article is licensed under a Creative Commons Attribution 4.0 International License, which permits use, sharing, adaptation, distribution and reproduction in any medium or format, as long as you give appropriate credit to the original author(s) and the source, provide a link to the Creative Commons license, and indicate if changes were made. The images or other third party material in this article are included in the article's Creative Commons license, unless indicated otherwise in a credit line to the material. If material is not included in the article's Creative Commons license and your intended use is not permitted by statutory regulation or exceeds the permitted use, you will need to obtain permission directly from the copyright holder. To view a copy of this license, visit http://creativecommons.org/licenses/by/4.0/.
} 
$\mathrm{Al}$ stress. For example, Norway spruce (Picea abies) or birch (Betula pendula) may endure $\mathrm{Al}$ concentrations of up to $3 \mathrm{mM}$ in the soil; however, an $\mathrm{Al}$ concentration below $50 \mu \mathrm{M}$ noticeably suppresses root elongation in Arabidopsis ${ }^{7}$. Most woody plants grow naturally in acidic soil and have evolved specific mechanisms to cope with high $\mathrm{Al}$ stress ${ }^{8}$. Therefore, deciphering the mechanism underlying the tolerance of woody plants to $\mathrm{Al}$ stress could help us understand the same process in crops and facilitate the use of gene-engineering strategies to improve $\mathrm{Al}$ tolerance in crop plants.

Correspondingly, a series of transporter genes responsible for $\mathrm{Al}$-activated exudation of malate or citrate have been reported. First, TaALM1 (Triticum aestivum Alactivated malate transporter) was identified as a malate anion efflux transporter for $\mathrm{Al}$ resistance ${ }^{9}$. In Arabidopsis and rape (Brassica napus), homologs of TaALM1 were similarly identified as $\mathrm{Al}^{3+}$-enhanced malate transporters ${ }^{10,11}$. Through the map-based cloning method, another gene family for $\mathrm{Al}$ resistance, known as MATE (multidrug and toxic compound extrusion) transporters, was identified in sorghum ${ }^{12}$. Several MATE orthologs that function as citrate transporters were then isolated in Arabidopsis (AtMATE1), maize (ZmMATE), rice bean $\left(\right.$ VuMATE), and rice $(O s F R D 1)^{13}$. More recent evidence showed that the abundance of these transporter families could also be transcriptionally regulated. Two zinc-finger proteins, namely, STOP1 from Arabidopsis and ART1 from rice, can directly regulate the $\mathrm{Al}$-induced expression of ALMT1 and AtMATE ${ }^{14,15}$. Furthermore, the WRKY transcription factor WRKY46 can bind the ALMT1 promoter to suppress its expression during $\mathrm{Al}$ stress, likely as part of a negative feedback loop ${ }^{16}$. In addition to $\mathrm{Al}$ chelation using organic acids, another effective strategy for $\mathrm{Al}$ exclusion is the absorption of $\mathrm{Al}$ by plant cell wall polysaccharides. At a high $\mathrm{Al}$ concentration in the environment, barley (Hordeum vulgare) may absorb $85 \%$ of the peripheral $\mathrm{Al}$ into its root cell walls ${ }^{17}$, and the giant alga Chara coralline may even absorb up to $99.9 \%$ of total $\mathrm{Al}$ into its cell walls ${ }^{18}$.

The four-carbon amino acid gamma-aminobutyric acid (GABA) functions as an inhibitory neurotransmitter in animals $^{19}$. In plants, GABA was found to regulate the responses to various abiotic stresses, such as heat, cold, touch, or hypoxia stress, as well as biotic stresses, including herbivory, wounding, and pathogen infection. GABA signaling also regulates the balance of $\mathrm{C}: \mathrm{N}$ or the cytosolic $\mathrm{pH}^{20}$. GABA is biosynthesized from glutamate through a $\mathrm{Ca}^{2+}$-calmodulin-related enzyme, decarboxylase (GAD), in plants. GABA can also be degraded in mitochondria through the GABA shunt, which contains two continuous steps from the tricarboxylic acid cycle. During the GABA shunt cycle, GABA is converted to succinic semialdehyde by GABA transaminase (GABA-T), and then, succinic semialdehyde is oxidized to succinate by succinic-semialdehyde dehydrogenase (SSADH), coupled with NADH production ${ }^{19,21}$. In Arabidopsis, salt stress induces the transcriptional upregulation of GAD and GAD2, resulting in a high level of GABA. Consistent with this, the pop 2 mutant, which is deficient in GABA-T, is very sensitive to ionic stress, such as salt stress, but insensitive to osmotic stress ${ }^{22}$. GABA has also been reported to regulate the malate-transporting plasma membrane channel during $\mathrm{Al}$ stress in wheat ${ }^{23,24}$, but the mechanism by which GABA enhances plant tolerance to $\mathrm{Al}$ needs to be investigated.

Liriodendron is a genus of the magnolia family that has two species, namely, L. chinense and L. tulipifera. Both of them are widely cultivated horticultural trees in China that produce high-quality timber ${ }^{25}$. Investigating how Liriodendron copes with abiotic stress, such as $\mathrm{Al}$ toxicity, is therefore of great ecological and economic value. In this study, we studied how hybrid Liriodendron responds to $\mathrm{Al}$ stress by using a quantitative iTRAQ proteomics approach. Using our available transcriptome data of $L$. chinense as a reference, we successfully isolated 198 proteins that showed significant differential expression after exposure to $\mathrm{Al}$ stress; this set included proteins required for energy metabolism, antioxidant activity, and defense response. Among these proteins, we detected upregulation of a putative GAD homologue after $\mathrm{Al}$ stress, accompanied by increased accumulation of the AlMT channel protein. The malate content and GAD-dependent GABA content were also increased after $\mathrm{Al}$ stress; physiological analysis showed that suppressing GABA biosynthesis aggravated, while application of exogenous GABA attenuated, the Al toxicity-mediated damage to hybrid Liriodendron viability. In addition, we found that the role that GABA plays in mediating $\mathrm{Al}$ stress resistance is conserved in both poplar and Arabidopsis. Thus, our findings suggest a new and conserved mechanism by which GABA enhances the tolerance of hybrid Liriodendron to $\mathrm{Al}$ stress through AlMT channel-dependent malate efflux.

\section{Materials and methods \\ Plant materials and Al treatment}

In this study, plantlets derived from the L. chinense somatic embryogenesis system were used as previously reported $^{26}$. In brief, embryogenic calli were induced from immature seeds and grown on the induction medium, and then, the induced calli were moved into liquid culture to promote their growth for 2 or 3 weeks. The embryogenic cells were shifted to solid medium for 4-5 weeks to induce seedling generation. The regenerated seedlings were transplanted to 0.5 - $\mathrm{L}$ pots with fine soil under greenhouse conditions (relative humidity of $50-70 \%$, $25^{\circ} \mathrm{C}$, white light at $800 \mu \mathrm{mol}$ photons $\mathrm{m}^{-2} \mathrm{~s}^{-1}$ ). Each pot 
was watered with $300 \mathrm{~mL}$ of nutrient solution containing $\mathrm{KNO}_{3}(1 \mathrm{mM}), \mathrm{Ca}\left(\mathrm{NO}_{3}\right)_{2}(1 \mathrm{mM}), \mathrm{KH}_{2} \mathrm{PO}_{4}(0.1 \mathrm{mM})$, $\mathrm{MgSO}_{4}(0.5 \mathrm{mM}), \mathrm{H}_{3} \mathrm{BO}_{3}(20 \mu \mathrm{M}), \mathrm{MnCl}_{2}(2 \mu \mathrm{M}), \mathrm{ZnSO}_{4}$ $(2 \mu \mathrm{M}), \mathrm{CuSO}_{4}(0.5 \mu \mathrm{M}),\left(\mathrm{NH}_{4}\right)_{6} \mathrm{Mo}_{7} \mathrm{O}_{24}(0.065 \mu \mathrm{M})$, and Fe-EDTA $(20 \mu \mathrm{M})$ every 5 days. The nutrient solutions containing the indicated $\mathrm{AlCl}_{3}$, GABA or $\mathrm{AlCl}_{3}+\mathrm{GABA}$ concentration were used for the $\mathrm{Al}$ stress treatments.

\section{Chlorophyll fluorescence analysis}

Plant leaves after different treatments were collected for chlorophyll fluorescence intensity analysis using a chlorophyll fluorometer (Heinz Walz GmbH, Effeltrich, Germany ${ }^{27}$. Each detached leaf was placed in the dark for 30 min for dark adaptation. Then, the maximum quantum yield of PSII was monitored as $\mathrm{Fv} / \mathrm{Fm}$. The maximum fluorescence $(\mathrm{Fm})$ was measured with $4000 \mu \mathrm{mol} \mathrm{s}^{-1} \mathrm{~m}^{-1}$ light with a 0.8-s pulse. Every analysis was repeated at least three times.

\section{Analysis of the $\mathrm{H}_{2} \mathrm{O}_{2}$ and $\mathrm{O}_{2}{ }^{-}$content}

The $\mathrm{H}_{2} \mathrm{O}_{2}$ content was determined using xylenol orange $^{28}$. In brief, hybrid Liriodendron leaf tissue $(1 \mathrm{~g})$ was collected after different treatments and homogenized in $5 \mathrm{~mL}$ of $\mathrm{HClO}_{4}$ solution $(0.2 \mathrm{M})$ in a cold room at $4{ }^{\circ} \mathrm{C}$. After allowing the mixture to stand for $5 \mathrm{~min}$, the supernatant was obtained after $10 \mathrm{~min}$ of centrifugation at $10,000 \times g$, and then, $100 \mu \mathrm{l}$ of the supernatant was added to $1 \mathrm{~mL}$ of reaction buffer to analyze $\mathrm{H}_{2} \mathrm{O}_{2}$ content; the reaction was processed at room temperature for $1 \mathrm{~h}$. The $\mathrm{H}_{2} \mathrm{O}_{2}$ level was measured by calculating the absorbance at $560 \mathrm{~nm}$ based on an $\mathrm{H}_{2} \mathrm{O}_{2}$ standard curve.

The $\mathrm{O}_{2}{ }^{-}$content was determined according to a previously published method ${ }^{29}$. The supernatant $(100 \mu \mathrm{l})$ was incubated with $1 \mathrm{~mL}$ of the reaction mixture with $50 \mathrm{mM}$ potassium phosphate buffer ( $\mathrm{pH} 7.0$ ), $10 \mathrm{mM}$ hydroxylamine hydrochloride, $17 \mathrm{mM}$ sulfanilic acid, and $7 \mathrm{mM}$ $\alpha$-naphthyl. The absorbance at $530 \mathrm{~nm}$ was monitored, and the $\mathrm{O}_{2}{ }^{-}$level was measured based on an $\mathrm{O}_{2}{ }^{-}$ standard curve.

\section{Lipid peroxidation analysis}

Lipid peroxidation was analyzed using the thiobarbituric acid-reacting substances (TBARS) method ${ }^{27}$. Leaf samples of hybrid Liriodendron $(1 \mathrm{~g})$ were frozen quickly in liquid nitrogen and homogenized using $10 \mathrm{~mL}$ of extraction buffer with trichloroacetic acid (TCA) at $10 \%$. The extract was centrifuged for $20 \mathrm{~min}$ at $10,000 \times g$, and then, the supernatant was used for further analysis. One milliliter of supernatant was added to $4 \mathrm{~mL}$ of reaction buffer containing $0.6 \%$ thiobarbituric acid and 20\% TCA, and the mixture was incubated at $95^{\circ} \mathrm{C}$ for $30 \mathrm{~min}$. Then, the reaction was stopped by rapid cooling in an ice bath. After the reaction had cooled to room temperature, the mixture was centrifuged at $10,000 \times g$ for $10 \mathrm{~min}$, and the absorbance of the supernatant was monitored at 532 and $600 \mathrm{~nm}$. The difference between the absorbance of the supernatant at $532 \mathrm{~nm}$ and that at $600 \mathrm{~nm}$ was measured, and the MDA level was calculated as previously described $^{27}$.

\section{RNA extraction and RT-qPCR analysis}

For quantitative RT-PCR analysis, hybrid Liriodendron leaves after different treatments were used for total RNA extraction using TRIzol reagent (Tiangen, China). The synthesis of first-strand cDNA and quantitative RT-PCR were performed using a previously reported method ${ }^{28}$. The primers used for RT-qPCR are listed in Supplemental Table 2. For each sample, three individual repeats of biological experiments were used for statistical analysis.

\section{Antioxidant enzyme activity measurements}

Leaf tissue $(\sim 1 \mathrm{~g})$ was collected for enzyme activity analysis. Different antioxidant enzyme activities, including ascorbate peroxidase (APX), glutathione reductase (GR), monodehydroascorbate reductase (MDHAR), and dehydroascorbate reductase (DHAR) activities, were analyzed as previously described ${ }^{27}$. The protein content was calculated using the Bradford method ${ }^{29}$.

\section{Analysis of GABA content and GAD enzyme activity}

Measurement of the GABA content in leaf extracts was performed as previously described ${ }^{30}$. In brief, $\sim 10 \mathrm{~g}$ of leaf sample was powdered in a Falcon tube and extracted using $10 \mathrm{~mL}$ of $80 \%(\mathrm{v} / \mathrm{v})$ ethanol. The extraction buffer was collected and centrifuged for $10 \mathrm{~min}$ at $1200 \times g$ and $4{ }^{\circ} \mathrm{C}$, and the supernatant was removed and filtered using Millipore filter paper. The filtration was repeated three times, and the filtrates were combined and dried on a rotary evaporator until the ethanol completely evaporated. Then, the dried residue was dissolved in $1 \mathrm{~mL}$ of water, and $1 \mathrm{~mL}$ of methanol containing 2-hydroxynaphthaldehyde $(2.5 \% \mathrm{w} /$ v) was added to the dissolved GABA for derivatization. Then, $0.5 \mathrm{~mL}$ of boric acid- $\mathrm{NaOH}(\mathrm{pH} 8.5)$ was added to neutralize the solution. The resultant sample was dried for $20 \mathrm{~min}$ at $85^{\circ} \mathrm{C}$ and cooled to room temperature. The residue was dissolved in $5 \mathrm{~mL}$ of methanol for further analysis. HPLC analysis was performed using an Agilent 1200 HPLC instrument. Approximately $5 \mu$ of the solution was injected onto a reversed-phase SB-C18 column with a methanol gradient system ( $2 \mathrm{~min}$ of $60 \%$ methanol, $5 \mathrm{~min}$ of $70 \%$ methanol, $8 \mathrm{~min}$ of $80 \%$ methanol, $10 \mathrm{~min}$ of $90 \%$ methanol, and $12 \mathrm{~min}$ of $50 \%$ methanol) with a flow rate of $0.8 \mathrm{~mL} / \mathrm{min}$. A UV detector at $254 \mathrm{~nm}$ was used to monitor the GABA content. The GABA content was analyzed by comparison with the retention time of a standard.

GAD activity was calculated by measuring the conversion ratio of the substrate glutamate to $\mathrm{GABA}^{22}$. Approximately $1 \mathrm{~g}$ of plant leaf sample was extracted in 
$10 \mathrm{~mL}$ of reaction buffer containing $80 \mathrm{mM}$ sodium phosphate $(\mathrm{pH} \mathrm{5.6)}$ and $100 \mathrm{mM} \mathrm{L}$-glutamate and then kept for $60 \mathrm{~min}$ at $40^{\circ} \mathrm{C}$. Then, the reaction was stopped at $90^{\circ} \mathrm{C}$. The reaction was cooled and centrifuged for $10 \mathrm{~min}$ at $1200 \times g$, and then, the supernatant was taken for GAD enzyme activity analysis as reported previously ${ }^{22}$.

\section{Proline content measurement}

Pro accumulation in hybrid Liriodendron leaves was measured using a previously described method $^{27}$, using LPro as a standard. In brief, $\sim 1 \mathrm{~g}$ of leaves was collected and extracted using $3 \%$ sulfosalicylic acid in a cold room. The supernatant was obtained after centrifugation at 12,000 $\times$ $g$ for $10 \mathrm{~min}$ at $4{ }^{\circ} \mathrm{C}$. An aliquot $(2 \mathrm{~mL})$ of supernatant and ninhydrin solution containing $2.5 \%$ [w/v] ninhydrin, $40 \%$ $6 \mathrm{M}$ phosphoric acid, and $60 \%$ [v/v] glacial acetic acid was reacted at $100^{\circ} \mathrm{C}$ for $30 \mathrm{~min}$, and the reaction was stopped by adding ice for quick cooling. Then, $5 \mathrm{~mL}$ of toluene was added, and the solution was incubated at room temperature overnight. The proline content was monitored by measuring the absorbance at $520 \mathrm{~nm}$ using a spectrophotometer.

\section{Relative root growth (RRG) analysis}

RRG values were determined as previously reported ${ }^{2}$. The seeds were surface-sterilized and sown in Murashige and Skoog (MS) medium for 3 days under light conditions at $60 \mu \mathrm{mol}$ photons $\mathrm{m}^{-2} \mathrm{~s}^{-1}$, and the initial root length was measured. Then, half of the seedlings were shifted to MS medium containing different concentrations of $\mathrm{AlCl}_{3}$, while the remaining half of the seedlings continued to grow on the same MS medium without $\mathrm{Al}$ stress. After 5 days of growth under the same light conditions, the root length was monitored using a ruler, and the degree of inhibition of root elongation is presented as the percentage of RRG.

\section{Total leaf protein extraction}

Total leaf proteins were extracted from frozen samples using phenol extraction buffer as previously described ${ }^{31}$. Briefly, $10 \mathrm{~g}$ of leaf tissue was quickly frozen and ground in liquid nitrogen using a mortar and pestle, followed by extraction in $10 \mathrm{~mL}$ of ice-cold protein extraction buffer (100 mM Tris- $\mathrm{HCl}$ buffer (pH 7.8), $100 \mathrm{mM} \mathrm{KCl,} 1 \% \mathrm{v} / \mathrm{v}$ Triton X-100, $1 \% \mathrm{v} / \mathrm{v} \beta$-mercaptoethanol, $50 \mathrm{mM} \mathrm{L-}$ ascorbic acid, $1 \mathrm{mM}$ phenylmethanesulfonyl fluoride). The supernatant was obtained by centrifugation at $12,000 \times g$ for $10 \mathrm{~min}$ and mixed with an equal volume of Tris-phenol buffer (100 mM Tris, $\mathrm{pH}$ 8.0). The mixture was vortexed thoroughly, and the upper phenol phase was collected after centrifugation at $12,000 \times g$ at $4{ }^{\circ} \mathrm{C}$ for $30 \mathrm{~min}$. Finally, five volumes of methanol containing $10 \mathrm{mM}$ ammonium acetate were added to the upper phenol phase. The mixture was placed at $-20^{\circ} \mathrm{C}$ overnight, and the protein pellet was obtained by centrifugation at $12,000 \times g$ for $15 \mathrm{~min}$. The wet pellet was washed with cold acetone and $0.1 \% \beta$-mercaptoethanol three times, and the washed pellet was then dried in air. The dried pellet was stored at $-80^{\circ} \mathrm{C}$ for further use or dissolved in Tris- $\mathrm{HCl}$ buffer ( $\mathrm{pH} 8.5,40 \mathrm{mM})$ containing urea (7 M), EDTA ( $2 \mathrm{mM})$, thiourea (2 M), CHAPS ( $4 \% \mathrm{v} /$ $\mathrm{v})$, and PMSF $(1 \mathrm{mM})$ at a final concentration of $10 \mathrm{mg} /$ $\mathrm{mL}$ for the next proteomic analysis. The protein solution was sonicated at $200 \mathrm{~W}$ for $15 \mathrm{~min}$ to promote dissolution and then centrifuged at $12,000 \times g$ for $15 \mathrm{~min}$ at $4{ }^{\circ} \mathrm{C}$. The pellet was discarded, and the supernatant was transferred to another tube. Then, $10 \mathrm{mM}$ DTT was added to the protein solution to avoid disulfide bond formation. Iodoacetamide (IAM) was added at $55 \mathrm{mM}$ to the protein solution under dark conditions to covalently block cysteines. Finally, the protein pellet was obtained by adding 5 volumes of cold acetone at $-20^{\circ} \mathrm{C}$ for $2 \mathrm{~h}$. The pellet was dried again and dissolved using $500 \mu \mathrm{l}$ of TEAB (tetraethylammonium bromide, $0.5 \mathrm{M}$ ), and the supernatant was collected after centrifugation at $12,000 \times g$ for $15 \mathrm{~min}$ in a cold room for proteomic analysis. The protein concentration was quantified using the Bradford method and a Bio-Rad protein assay kit (Bio-Rad, USA).

\section{ITRAQ mass spectrometry analysis}

The protein $(100 \mu \mathrm{g})$ extracted from the leaves as described above was used for iTRAQ analysis as follows. Briefly, the extracted protein was first digested to peptides by Gold Trypsin (Promega, Madison, WI, USA) at a ratio of 30:1 (protein:trypsin) at room temperature for $16 \mathrm{~h}$ and then dried by vacuum centrifugation. The dried peptides were then redissolved in TEAB buffer $(0.5 \mathrm{M})$ as recommended for the 8-plex iTRAQ reagents (AB Sciex Inc., MA, USA). The extracted protein from different samples was digested as described above and labeled with iTRAQ reagents with the 113 to 117 isobaric tags at room temperature for $2 \mathrm{~h}$. After labeling, the peptide mixture was dried through vacuum centrifugation and redissolved in $4 \mathrm{~mL}$ of strong cation exchange (SCX) solvent containing $25 \mathrm{mM} \mathrm{NaH}_{2} \mathrm{PO}_{4}, 25 \%$ acetonitrile, and $10 \mathrm{mM}$ ammonium formate $(\mathrm{pH}$ 2.7). The peptide mixtures were separated by an Ultremex SCX column $(4.6 \times 250 \mathrm{~mm})$ using a Shimadzu LC-20AB HPLC pump system (Shimadzu Co., Kyoto, Japan). The peptide fraction was eluted at a flow rate of $1 \mathrm{~mL} \mathrm{~min}^{-1}$ with stable $5 \%$ buffer B containing $1 \mathrm{M} \mathrm{KCl}, 25 \mathrm{mM} \mathrm{NaH}_{2} \mathrm{PO}_{4}$, and $25 \% \mathrm{ACN}$ at $\mathrm{pH} 2.7$ for $7 \mathrm{~min}$, followed by a linear gradient of $5-60 \%$ buffer B over $20 \mathrm{~min}$ and $60-100 \%$ buffer B over $2 \mathrm{~min}$. Finally, elution was performed with $100 \%$ buffer B. The absorbance at $214 \mathrm{~nm}$ was selected to monitor the elution peak, and a total of 20 fractions were collected. Each SCX fraction was desalted and redissolved in buffer C (5\% $\mathrm{ACN}$ and $0.1 \%$ formic acid), and the supernatant was 
collected by centrifugation at $20,000 \times g$ for $10 \mathrm{~min}$. Finally, $5 \mu \mathrm{L}$ of supernatant was loaded for HPLC-mass spectrometry analysis by Shimadzu LC-20 AD nanoHPLC (Shimadzu Co. Kyoto, Japan) with a C18 column (200 $\mu \mathrm{m}$ inner diameter), and the peptide was eluted with 5\% buffer D (95\% ACN, 0.1\% formic acid) for $5 \mathrm{~min}$, followed by $3-35 \%$ buffer $\mathrm{D}$ over $35 \mathrm{~min}, 60-80 \%$ buffer D over 2 min, and a final wash with $80 \%$ buffer $\mathrm{D}$ at a flow rate of $250 \mathrm{~nL} / \mathrm{min}$. The eluted peptides were then sprayed into the injection port of a TripleTOF 5600 system (AB SCIEX, Concord, ON, Canada) equipped with a Nanospray III source under a spray voltage of $2.5 \mathrm{kV}, 30 \mathrm{psi} \mathrm{N}$ gas, 15 psi nebulizer gas, and a heater temperature of $150^{\circ} \mathrm{C}$. Full-scan mass spectra were obtained by the Orbitrap analyzer in information-dependent acquisition (IDA) mode with a mass range of $100-2400 \mathrm{~m} / z$ at a high detection resolution of over 30,000 (FWHM). The 30 most intense precursor ion peaks with a threshold over $120 \mathrm{cps}$ and a $2+$ to $5+$ charge state were selected for collision-induced fragmentation. Dynamic exclusion was employed within $40 \mathrm{~s}$ to prevent repetitive selection of the peptides.

\section{Bioinformatics analysis}

The raw LC-MS/MS data files were converted to generic Mascot files (mgf) by Proteome Discoverer 1.2 software, and searching was performed with the $L$. chinense proteome database $e^{25}$. Trypsin was used as the proteolytic enzyme, and one missed cleavage was permitted. The peptide mass and fragment mass tolerance values were 10 ppm and $0.1 \mathrm{Da}$, respectively. The search parameters included iTRAQ 8-plex quantification, oxidation of methionine residues, and pyroglutamate formation of $\mathrm{N}$ terminal glutamine residues as variable residues and carbamidomethyl formation of cysteine residues as fixed modifications. Only the peptides with a significant score over 20 with a $99 \%$ confidence interval and false discovery rates (FDR) $<1.5 \%$ were used for quantification analysis, and cutoffs higher than 1.5- or lower than 0.6-fold with a $p$-value $<0.05$ were identified as significantly differentially expressed proteins.

\section{Results}

\section{Al stress impedes photosynthesis in hybrid Liriodendron} and causes membrane lipid oxidative damage

To understand the mechanism underlying the hybrid Liriodendron $\mathrm{AlCl}_{3}$ stress response, we first aimed to optimize our experimental conditions. Plant photosynthesis efficiency is a good way to estimate physiological plant health in response to various stressors. We therefore determined how $\mathrm{AlCl}_{3}$ toxicity affects leaf photosynthesis by examining the dose-dependent response of the $\mathrm{Fv} / \mathrm{Fm}$ ratio to increasing $\mathrm{AlCl}_{3}$ concentrations. The $\mathrm{Fv} / \mathrm{Fm}$ ratio is an efficient indicator of a leaf's photosynthetic ability.
We found that treating hybrid Liriodendron with $\mathrm{AlCl}_{3}$ concentrations from 5 to $50 \mu \mathrm{M}$ gradually reduced the $\mathrm{Fv} /$ Fm ratio: once the $\mathrm{AlCl}_{3}$ concentration reached $100 \mu \mathrm{M}$, the Fv/Fm ratio decreased rapidly (Supplemental Fig. 1). Based on our dose-response curve, we chose to use an $\mathrm{AlCl}_{3}$ concentration of $30 \mu \mathrm{M}$ for further experiments in this study.

We then proceeded to further characterize hybrid Liriodendron leaf viability/photosynthetic capability in response to $30 \mu \mathrm{M} \mathrm{AlCl}$. We found that hybrid Liriodendron leaves exposed to $\mathrm{AlCl}_{3}$ turned yellowish after 7 days of treatment, while the $\mathrm{Fv} / \mathrm{Fm}$ ratio decreased gradually during this time and decreased from $\sim 0.803$ to $\sim 0.427$. In control plants, the $\mathrm{Fv} / \mathrm{Fm}$ ratio was stably maintained at $\sim 0.79$ (Fig. 1A, B). Lipid peroxidation is generally used to assess the intensity of oxidative stress. Lipid peroxidation generates several reactive aldehydes, such as malondialdehyde (MDA); thus, the level of MDA is used to evaluate environmental oxidative stress. $\mathrm{AlCl}_{3}$ treatment also increased the level of MDA, reflecting membrane lipid oxidative damage. Furthermore, we found that the leaf transpiration rate and stomatal conductance levels, additional parameters that reflect photosynthetic activity, were also decreased after $\mathrm{AlCl}_{3}$ treatment (Fig. 1B). Thus, these data suggest that $\mathrm{AlCl}_{3}$ negatively affected the leaf viability and photosynthetic capability of the Liriodendron hybrid.

\section{Dynamic proteome profiling of hybrid Liriodendron in response to $\mathrm{Al}$ stress}

Next, we aimed to identify the genes are associated with the $\mathrm{Al}$ stress response in hybrid Liriodendron. To this end, we performed a proteomics study by using the iTRAQ proteomics approach, which allowed us to analyze differential protein abundance in hybrid Liriodendron leaves subjected to $30 \mu \mathrm{M} \mathrm{AlCl}_{3}$ treatment for $1,3,5$, and 7 days, using untreated plants as a control. Each sample for iTRAQ analysis was repeated with three biological replicates, and protein prediction and quantification were performed through Mascot software and public plant protein databases, as well as our own $L$. chinense transcriptome. Differentially abundant proteins were divided into three groups: group 1 ( 1 day of $\mathrm{AlCl}_{3}$ treatment/ untreated control), group 2 (3 days of $\mathrm{AlCl}_{3}$ treatment/ untreated control) and group 3 (5 days of $\mathrm{AlCl}_{3}$ treatment/untreated control). Proteins with a $>1.5$-fold change in abundance were regarded as having significantly increased expression; in contrast, the proteins with a $<0.6$ fold change in abundance were regarded as having significantly decreased expression. In total, we identified 198 proteins that presented significant changes after $\mathrm{AlCl}_{3}$ treatment (Fig. 2, Supplemental Tables 1 and 2). These 198 identified proteins were classified into 8 groups based on their biological function; most proteins belonged to the 


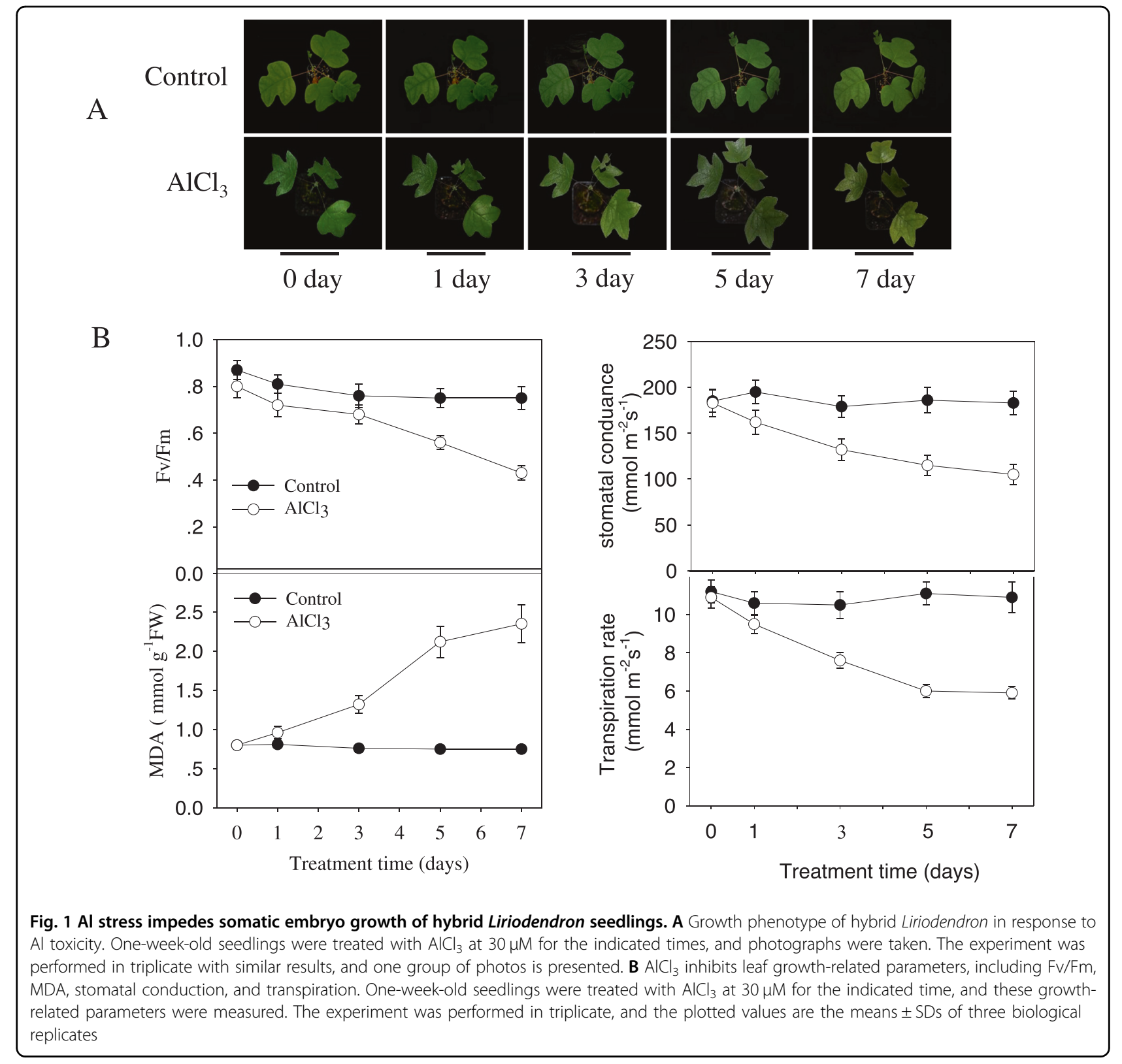

largest group of material and energy metabolism, followed by the group of plant hormone signaling and antioxidant proteins. Out of the 198 differentially regulated proteins, 39 proteins with increased expression and 50 proteins with decreased expression were constitutively upregulated or downregulated, respectively, at all time points.

We also performed a hierarchical cluster analysis to identify the proteins that were differentially expressed during $\mathrm{Al}$ stress. We noticed that the accumulation levels of antioxidant proteins, such as glutathione S-transferase (Lchi06330), monodehydrogenase reductase (Lchi27219), polyphenol oxidase (Lchi16057), peroxidase 17 (Lchi20649), peroxidase 72 (Lchi10272), and catalase isozyme 1 (Lchi14208), were upregulated. Several proteins associated with protein synthesis or stability, such as proteasome subunit alpha type-1 B (Lchi26499), plant UBX domaincontaining protein 4 (Lchi21723), aspartyl protease family protein (Lchi27243), and COP9 signalosome complex subunit 7 (Lchi31560), and proteins associated with epigenetic regulation, such as histone H2A (Lchi09914), thioredoxin M-type (Lchi12001), pre-mRNA-processing protein $40 \mathrm{~A}$ (Lchi23330), DEAD-box ATP-dependent RNA helicase 53 (Lchi32037), and putative DNA repair protein RAD23-3 (Lchi24553), were also differentially accumulated after $\mathrm{Al}$ stress. In addition, a series of transcription factors, such as zinc finger $\mathrm{CCCH}$ domain-containing protein (Lchi14090, Lchi14538), WRKY protein (Lchi09560, Lchi03796, Lchi13688), bZIP transcription factor 


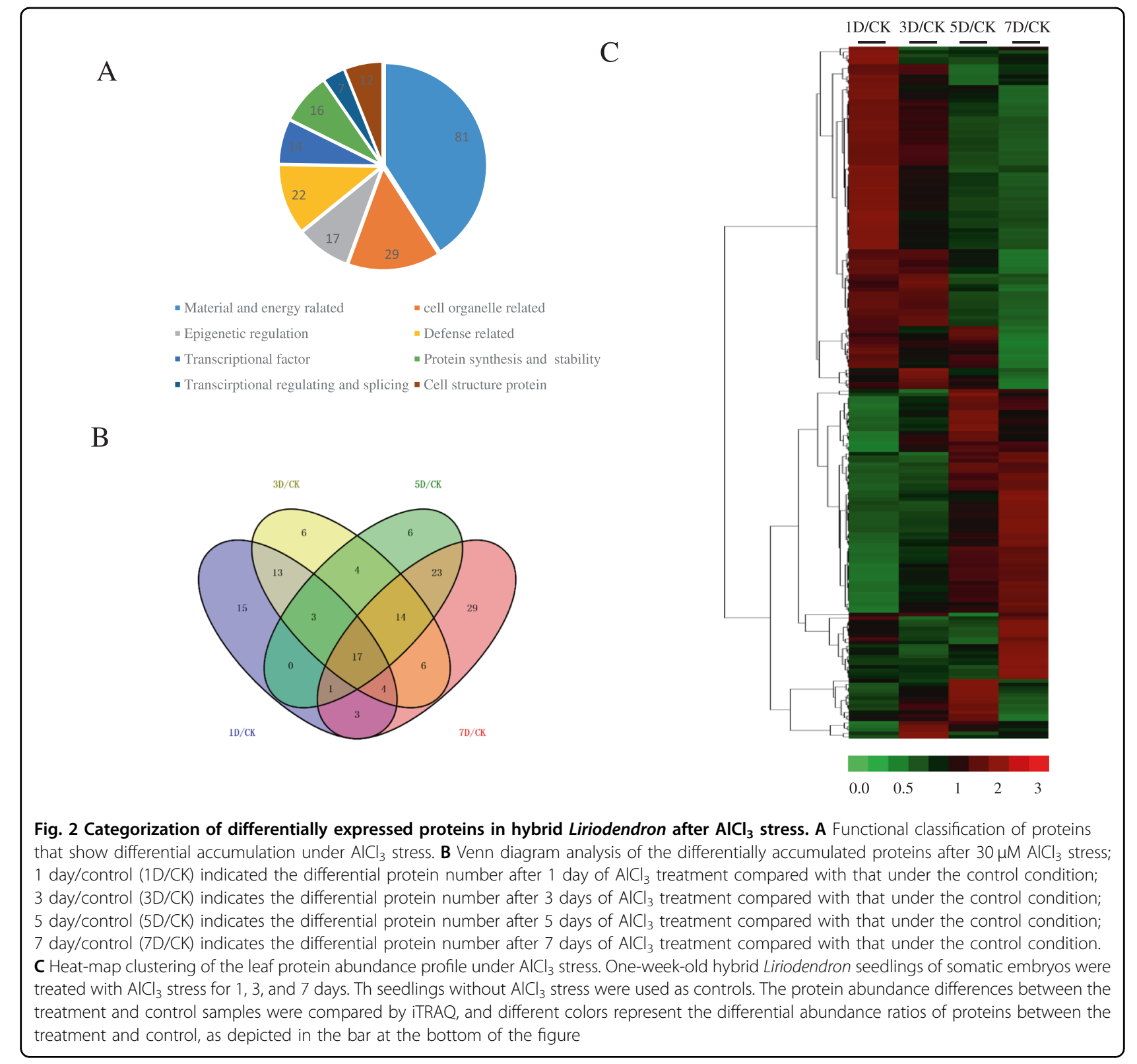

(Lchi10492, Lchi02202, Lchi09267), and MYB transcription factor (Lchi16241), were also differentially regulated after $\mathrm{Al}$ stress.

Organic acids have been reported to function as $\mathrm{Al}$ chelators when transported outside the cell, aiding $\mathrm{Al}$ toxicity avoidance ${ }^{4}$. Consistent with this, we found several proteins encoding homologs of malate acid transporters, namely, MATE1 (Lchi06125) and MATE2 (Lchi26133), that were upregulated by Al stress, indicating that they may be involved in enhancing the tolerance of hybrid Liriodendron to $\mathrm{Al}$ stress.

In Arabidopsis thaliana, STOP1 belongs to the nuclear zinc finger protein family; it can directly activate AtALMT1 or MATE expression and is involved in attenuating $\mathrm{H}^{+}$and $\mathrm{Al}^{3+}$ rhizotoxicity ${ }^{14}$. Our data also showed the upregulation of a zinc finger protein homologous to STOP1 (Lchi25591) in response to Al stress, suggesting a possible common mechanism between hybrid Liriodendron and other plants. These results indicate that our proteomics data indeed accurately reflect the translational response of hybrid Liriodendron to $\mathrm{Al}$ stress.

\section{Al treatment causes an increase in GAD enzyme activity and GABA synthesis}

In addition to proteins that have previously been implicated in the $\mathrm{Al}$ stress response, we also detected changes in the expression levels of homologs of GAD and 


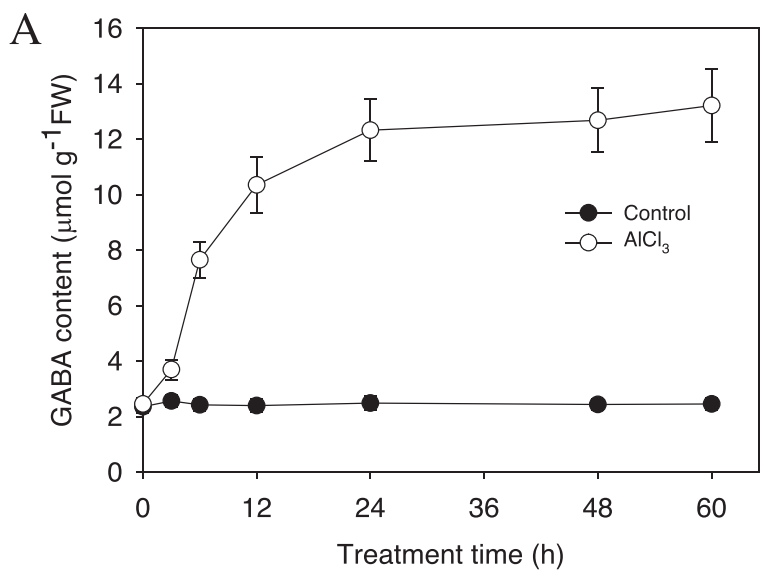

B

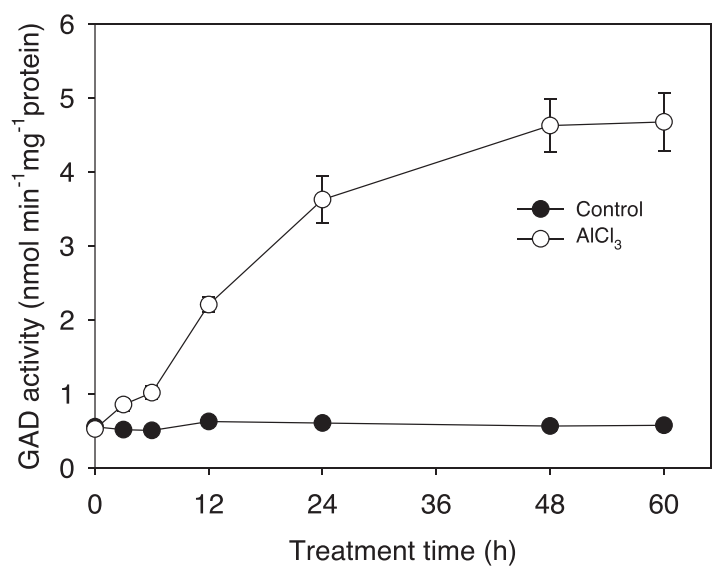

Fig. $3 \mathrm{AlCl}_{3}$ stress induces an increase in GABA content and GAD activity. One-week-old hybrid Liriodendron seedlings of somatic embryos were subjected to $30 \mu \mathrm{M} \mathrm{AlCl}_{3}$ stress for the indicated amount of time, after which the GABA content (A) and GAD activity (B) were measured. The experiment was performed in triplicate. The data represent the mean \pm SD of three biological replicates

succinic-semialdehyde dehydrogenase (SSADH), both of which are enzymes involved in the GABA biosynthesis pathway in plants ${ }^{32}$. GABA may act as a signaling molecule that is involved in different physiological processes, including growth, development, and defense responses. Our iTRAQ results showed that the abundance of two GAD homologs (Lchi33118 and Lchi05759) and one SSADH homolog (Lchi21261) was upregulated after 1 day or 3 days of $\mathrm{Al}$ stress treatment (Supplemental Table 1), suggesting a role for GABA signaling in the hybrid Liriodendron $\mathrm{Al}$ stress response.

To verify this hypothesis, we determined the GABA level in hybrid Liriodendron leaves after exposure to $\mathrm{Al}$ stress. $\mathrm{AlCl}_{3}$ treatment at $30 \mu \mathrm{M}$ induced a rapid increase in GABA content in the hybrid Liriodendron leaves, with the value reaching $10.35 \mu \mathrm{molg}^{-1} \mathrm{FW}$ after $24 \mathrm{~h}$ of treatment, a high level that was sustained during the following $36 \mathrm{~h}$ of treatment (Fig. 3A). In accordance with these data, we also found that GAD enzyme activity (responsible for GABA biosynthesis) increased similarly after $\mathrm{Al}$ stress. Al-induced GAD activity peaked after $48 \mathrm{~h}$ of $\mathrm{Al}$ stress and maintained a high level until $60 \mathrm{~h}$ of $\mathrm{AlCl} 3$ treatment (Fig. 3B). These data support our proteomics data showing that $\mathrm{Al}$ stress induces an increase in GAD protein abundance and indicates a potential role for GABA in the $\mathrm{Al}$ stress response in hybrid Liriodendron.

\section{GABA protects hybrid Liriodendron from oxidative damage under $\mathrm{Al}$ stress}

Our above iTRAQ results demonstrate that $\mathrm{Al}$ stress increases the expression of proteins encoding antioxidant enzymes, including catalase (Lchi14208), peroxidase (Lchi17145, Lchi20649, Lchi10272) and MDHAR (Lchi27219), which might have a role in scavenging ROS, such as $\mathrm{H}_{2} \mathrm{O}_{2}$ and $\mathrm{O}_{2}{ }^{-}$, which may accumulate in response to $\mathrm{Al}$ stress. To determine whether the $\mathrm{Al}$ stress response indeed leads to ROS production, we measured $\mathrm{Al}$-induced accumulation of ROS, focusing on $\mathrm{H}_{2} \mathrm{O}_{2}$ and $\mathrm{O}_{2}{ }^{-}$. We found that $\mathrm{Al}$ stress applied for 3 days induced rapid accumulation of $\mathrm{H}_{2} \mathrm{O}_{2}$ and $\mathrm{O}_{2}{ }^{-}$and that pretreatment with 


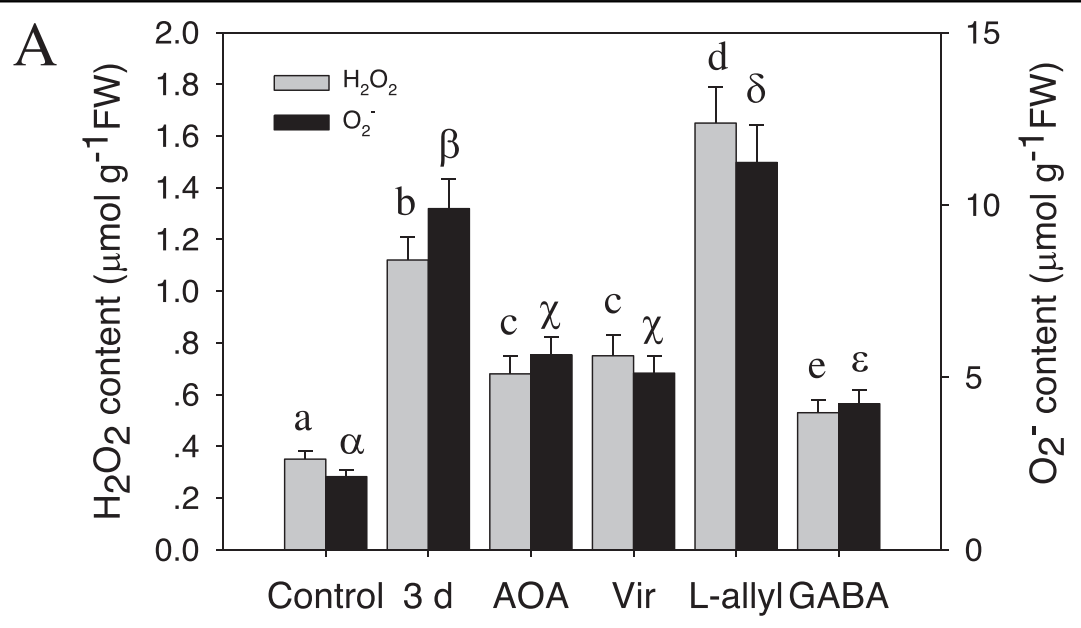

Treatment time

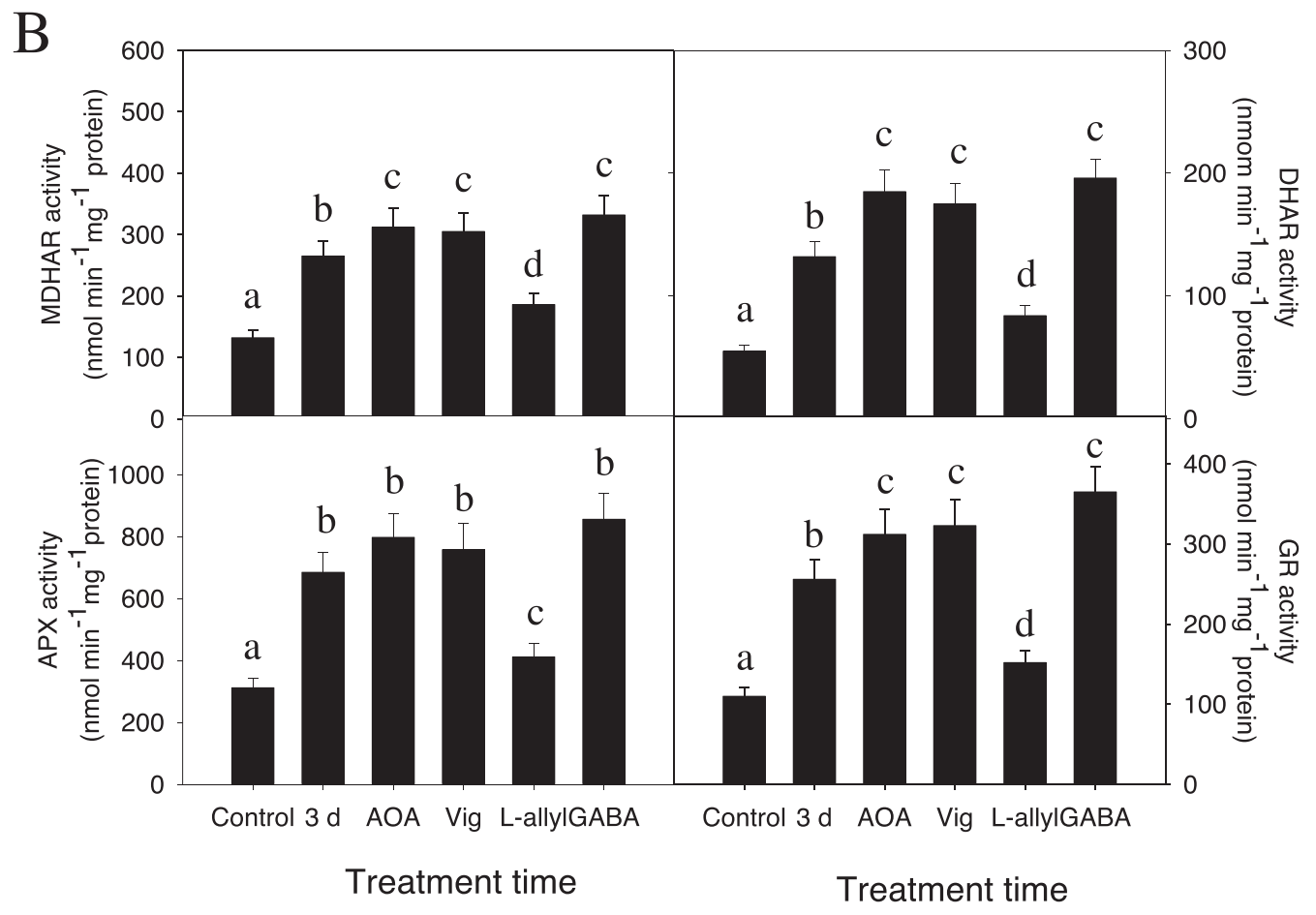

Fig. $4 \mathrm{AICl}_{3}$ stress induces an increase in ROS content and antioxidant enzyme activity. One-week-old hybrid Liriodendron seedlings of somatic embryos were subjected to $\mathrm{AlCl}_{3}$ stress or $\mathrm{AlCl}_{3}$ stress with additional aminooxyacetic acid (AOA), vigabatrin (Vir), L-allylglycine (L-allyl), or GABA for 3 days. Then, the ROS content, including $\mathrm{H}_{2} \mathrm{O}_{2}$ and $\mathrm{O}_{2}{ }^{-}(\mathbf{A})$, and antioxidant enzyme activities, including MDHAR, DHAR, APX and GR activities (B), were measured. Control: the sample without Al stress was used as the control; $3 \mathrm{~d}: 30 \mu \mathrm{M} \mathrm{AlCl}$ stress for 3 days; $\mathrm{AOA}: 30 \mu \mathrm{M} \mathrm{AlCl}{ }_{3}$ stress with the addition of $1 \mathrm{mM}$ aminooxyacetic acid for 3 days; Vir: $30 \mu \mathrm{M} \mathrm{AlCl}$ stress with the addition of $100 \mu \mathrm{M}$ vigabatrin for 3 days; L-allyl: $30 \mu \mathrm{M}$ AlCl 3 stress with the addition of $1 \mathrm{mM} \mathrm{L}$-allylglycine for 3 days; GABA: $30 \mu \mathrm{M} \mathrm{AlCl}_{3}$ stress with the addition of $10 \mathrm{mM} \mathrm{GABA}$ for 3 days. The experiment was performed in triplicate, and the data represent the mean \pm SD of three biological replicates. Different letters indicate statistically significant differences $(p<0.05)$ as determined by Tukey's multiple comparisons test

exogenous GABA could relieve Al-induced ROS generation (Fig. 4A). These results show that GABA plays a role in scavenging ROS in hybrid Liriodendron, which is also consistent with previous studies in plants.
To corroborate these results, we used chemical inhibitors that specifically act to alter the intracellular GABA concentration. Aminooxyacetic acid (AOA) and vigabatrin are putative GABA transaminase inhibitors and 


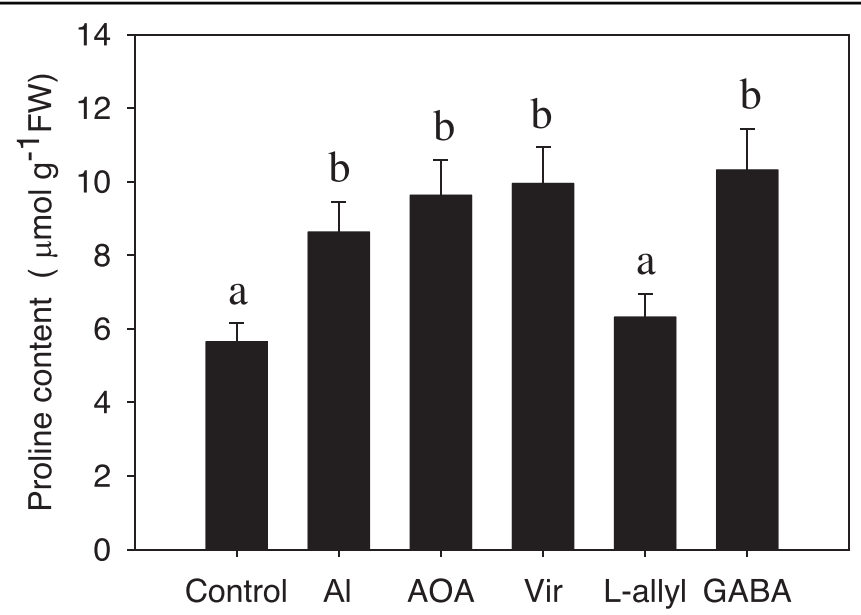

Fig. $5 \mathrm{AICl}_{3}$ stress induces intracellular proline accumulation. One-week-old hybrid Liriodendron seedlings of somatic embryos were subjected to $\mathrm{AlCl}_{3}$ stress (3 d) or $\mathrm{AlCl}_{3}$ stress with the addition of AOA, vigabatrin (Vir), L-allylglycine, or GABA for the indicated amount of time, after which the proline content was measured. The experiment was performed in triplicate, and the data represent the mean \pm SD of three biological replicates. Different letters indicate statistically significant differences $(p<0.05)$ as determined by Tukey's multiple comparisons test

suppress the conversion of GABA to SSDHA, thus causing an increase in the endogenous GABA content. Lallylglycine is a GADase inhibitor that suppresses the generation of GABA. Pretreatment with AOA or vigabatrin counteracted $\mathrm{AlCl}_{3}$-induced $\mathrm{ROS}$ accumulation (Fig. 4A) and enhanced the activities of antioxidant enzymes. This is consistent with an increase in GABA levels, while $\mathrm{L}$-allylglycine treatment increased $\mathrm{AlCl}_{3}$ induced ROS damage and reduced antioxidant enzyme activities (Fig. 4B). Similar to AOA or vigabatrin, additional GABA attenuated the $\mathrm{AlCl}_{3}$-induced increase in antioxidant enzyme activities (Fig. 4B), suggesting a putative role for GABA signaling in protecting hybrid Liriodendron from $\mathrm{AlCl}_{3}$-induced oxidative damage.

\section{GABA enhances proline biosynthesis during Al stress}

Proline contributes to the plant environmental stress response by altering cellular osmotic levels ${ }^{33}$. Proline-5carboxylate synthase (P5CS) and proline-5-carboxylate reductase (P5CR) are two essential enzymes that catalyze proline biosynthesis in plants ${ }^{34}$. We found that both the protein levels of P5CS (Lchi29824) and P5CR (Lchi04198) were significantly upregulated in hybrid Liriodendron in response to $\mathrm{Al}$ stress, suggesting that they may play a role in Al stress tolerance. To study this hypothesis, we monitored the proline level in hybrid Liriodendron subjected to $\mathrm{Al}$ stress. $\mathrm{Al}$ stress induced a marked increase in proline levels starting from 3 days after treatment, after which the levels slowly declined again (Fig. 5). Additional GABA treatment increased $\mathrm{Al}$-induced proline accumulation, which was maintained after 3 to 5 days of $\mathrm{Al}$ stress. Furthermore, treatment with the inhibitor AOA or vigabatrin or adding GABA directly strongly increased $\mathrm{AlCl}_{3}$-induced proline biosynthesis, while additional L-allylglycine treatment reduced $\mathrm{AlCl}_{3}$-induced proline biosynthesis, suggesting a novel role of GABA in proline biosynthesis during $\mathrm{Al}$ stress (Fig. 5).

\section{GABA increases citrate synthesis to combat Al toxicity}

Al treatment may trigger ALMT activity, leading to extracellular transport of malate or citrate and chelation of $\mathrm{Al}$ ions. Previous studies found that ALMT is responsible for malate exudation, while MATE exports citrate in most plants, such as Arabidopsis, rice and wheat ${ }^{35}$. We found that $\mathrm{Al}$ treatment indeed increased the accumulation of MATE1 (Lchi06125, named LchMATE1) and MATE2 (Lchi26133, named LchMATE2) homologs in hybrid Liriodendron (Supplemental Table 1 and Supplemental Fig. 2), suggesting a possible function of citrate exudation in hybrid Liriodendron $\mathrm{Al}$ stress tolerance. We next sought to confirm the functionality of LchMATE upregulation by measuring the extracellular citrate content in hybrid Liriodendron in response to $\mathrm{Al}$ stress. $\mathrm{AlCl}_{3}$ treatment induced a strong increase in citrate, a response that could be further enhanced through additional GABA treatment (Fig. 6A, B). Pretreatment with the enzyme inhibitors AOA and vigabatrin similarly increased citrate exudation, while L-allylglycine treatment reduced citrate exudation, suggesting that GABA signaling additionally controls organic acid-mediated chelation of $\mathrm{Al}$ as a stress response. We also investigated the change in malate in hybrid Liriodendron after $\mathrm{AlCl}_{3}$ or GABA treatment. Although $\mathrm{AlCl}_{3}$ treatment obviously increased the malate content, additional GABA treatment did not further increase the malate content (Supplemental Fig. 3), suggesting that malate metabolism is not the main pathway by which $\mathrm{GABA}$ protects against $\mathrm{AlCl}_{3}$ stress. 

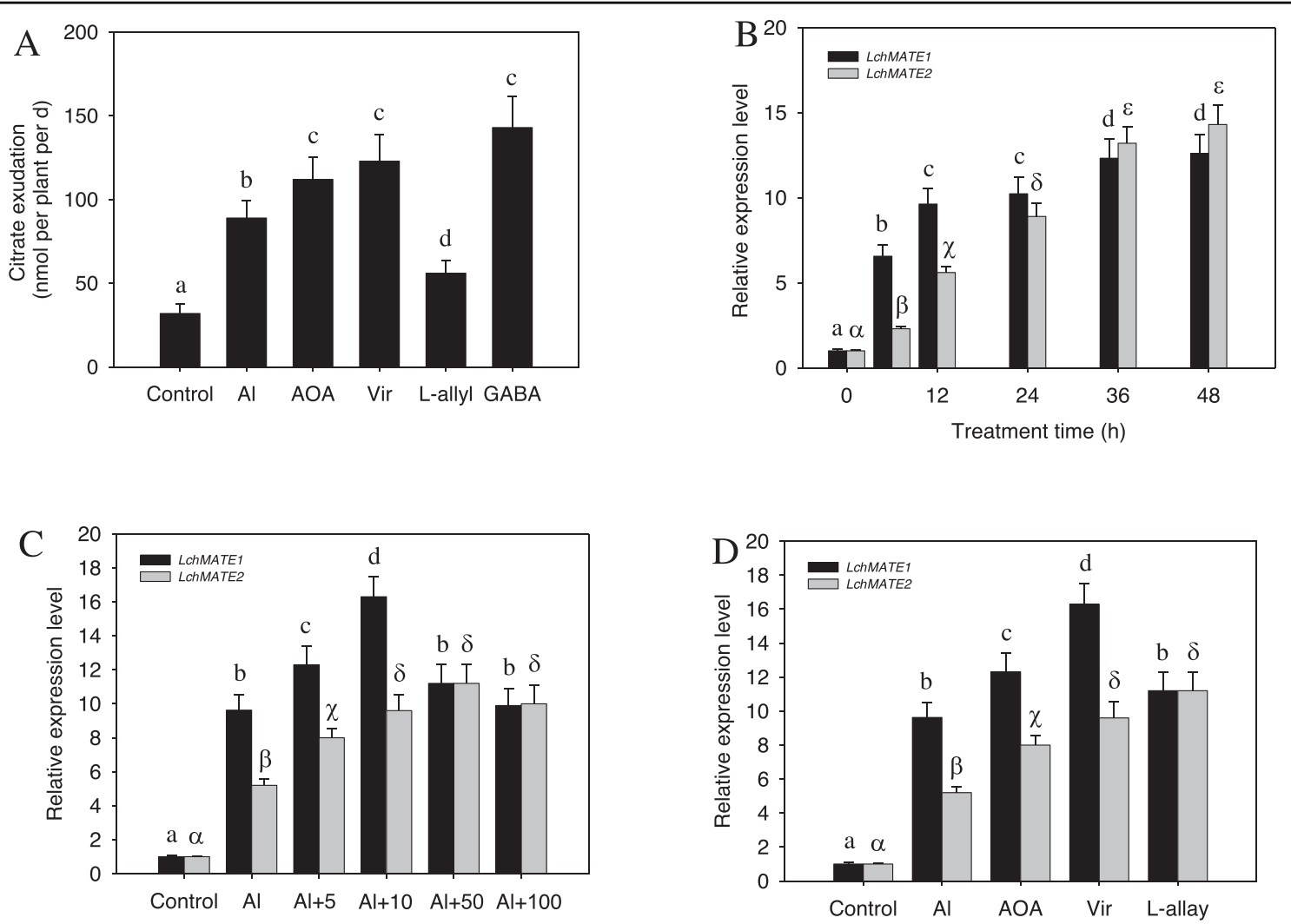

Fig. 6 GABA mediates increased LchMATE transcription and citrate exudation in response to $\mathrm{AlCl}_{3}$ stress in hybrid Liriodendron seedlings of somatic embryos. One-week-old hybrid Liriodendron seedlings of somatic embryos were subjected to $\mathrm{AlCl}_{3}$ stress or $\mathrm{AlCl}_{3}$ stress with the addition of $A O A$, vigabatrin $(V i r)$, L-allylglycine (L-allyl), or GABA, after which citrate exudation and LChMATE1/2 transcription were measured. The experiment was performed in triplicate, and the data represent the mean \pm SD of three biological replicates. Different letters indicate statistically significant differences $(p<0.05)$ as determined by Tukey's multiple comparisons test. $\mathbf{A}$ The effects of GABA or different inhibitors on citrate exudation after 3 days of treatment. One-week-old hybrid Liriodendron seedlings of somatic embryos were subjected to $30 \mu \mathrm{M} \mathrm{AlCl}_{3}$ stress or $30 \mu \mathrm{M} \mathrm{AlCl}$ stress with the addition of different inhibitors or GABA, respectively, for 3 days, and citrate exudation was measured. B $\mathrm{AlCl}_{3}$ stress induced the transcription of LChMATE1/2. One-week-old hybrid Liriodendron seedlings of somatic embryos were subjected to $30 \mu \mathrm{M} \mathrm{AlCl}$ stress for the indicated times, and the transcriptional level of LChMATE1/2 was measured by RT-qPCR analysis. C Effect of the GABA concentration on the Al-induced increase in $L C h M A T E 1 / 2$ transcription. One-week-old hybrid Liriodendron seedlings of somatic embryos were treated with $30 \mu \mathrm{M} \mathrm{AlCl}$ or $30 \mu \mathrm{M} \mathrm{AICl}$ supplemented with different concentrations of GABA for $24 \mathrm{~h}$, and the transcriptional level of LChMATE1/2 was measured by RT-qPCR analysis. Control: the sample without Al stress; $\mathrm{Al}: 30 \mu \mathrm{M} \mathrm{AlCl}_{3}$ treatment; $\mathrm{Al}+5: 30 \mu \mathrm{M} \mathrm{AlCl}$, with an additional $5 \mathrm{mM} \mathrm{GABA} ; \mathrm{Al}+10: 30 \mu \mathrm{M} \mathrm{AlCl}$ with an additional $10 \mathrm{mM}$ GABA; $\mathrm{Al}+50: 30 \mu \mathrm{M} \mathrm{AlCl} 3$ with an additional $50 \mathrm{mM}$ GABA; $\mathrm{Al}+100: 30 \mu \mathrm{M} \mathrm{AlCl}_{3}$ with an additional $100 \mathrm{mM}$ GABA. $\boldsymbol{D}$ Effect of different inhibitors on the Alinduced transcriptional increase in LChMATE1/2. One-week-old hybrid Liriodendron seedlings of somatic embryos were subjected to $30 \mu \mathrm{M} \mathrm{AICl}{ }_{3}$ stress or $30 \mu \mathrm{M} \mathrm{AlCl}_{3}$ with the addition of different inhibitors as described above for $24 \mathrm{~h}$, and the transcriptional level of LChMATE1/2 was measured by RTqPCR analysis

Next, we sought to determine whether regulation of LchMATE1 or LchMATE2 in response to $\mathrm{AlCl}_{3}$ stress occurs solely at the translation level or whether transcriptional regulation is also involved. Through RT-qPCR experiments, we found that $\mathrm{AlCl}_{3}$ induces a dosedependent transcriptional response in LchMATE1 or LchMATE2, with GABA synergistically further increasing the $\mathrm{AlCl}_{3}$-induced transcriptional levels of $L c h M A T E 1 / 2$ (Fig. 6C). Consistent with these results, AOA and vigabatrin treatment also coordinately increased $\mathrm{AlCl}_{3}$-induced citrate exudation, while L-allylglycine treatment exerted the opposite effect (Fig. 6D). There are two isomers of GABA in plants, namely, alpha-aminobutyric acid (AABA) and beta- aminobutyric acid (BABA). BABA has been indicated to enhance plant resistance to disease and abiotic stress. Many studies have shown the difference between BABA and GABA $^{36,37}$. As an isomer of GABA, AABA is not well studies. The hybrid Liriodendron was further treated with $\mathrm{AlCl}_{3}, \mathrm{GABA}$, and $\mathrm{AABA}$ to determine whether regulation of LChMATE1 or LChMATE2 was performed by this analog of GABA. The RT-qPCR data show that the transcription of LChMATE1 or LchMATE2 could hardly be regulated by AABA in hybrid Liriodendron (Supplemental Fig. 4).

Having found that $\mathrm{Al}$ stress in hybrid Liriodendron leads to increased GABA synthesis, which mediates downstream responses, such as ROS reduction and organic acid 

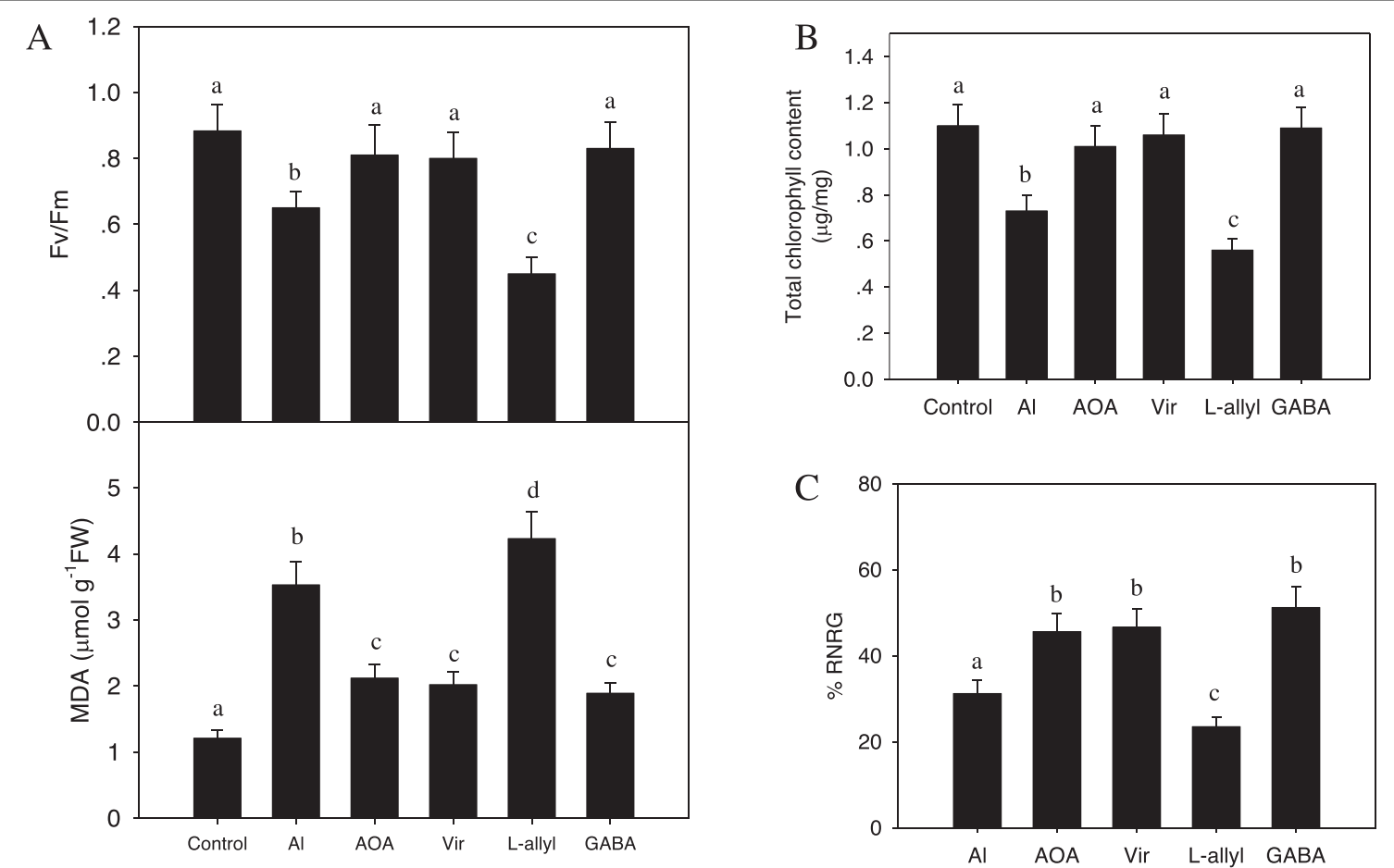

Fig. $7 \mathrm{GABA}$ alleviates the growth inhibitory effects of $\mathrm{AlCl}_{3}$ stress on hybrid Liriodendron. One-week-old hybrid Liriodendron seedlings of somatic embryos were subjected to $\mathrm{AlCl}_{3}$ stress or $\mathrm{AlCl}_{3}$ stress with an additional inhibitor as described above for 3 days. Leaf Fv/Fm, MDA content $(\mathbf{A})$, total chlorophyll content $(\mathbf{B})$ and relative root growth $(\mathbf{C})$ were measured. The experiment was performed in triplicate, and the data represent the mean \pm SD of three biological replicates. Different letters indicate statistically significant differences $(p<0.05)$ as determined by Tukey's multiple comparisons test

exudation, we investigated whether GABA can indeed protect hybrid Liriodendron from $\mathrm{AlCl}_{3}$-induced damage. We found that exogenous GABA treatment or treatment with AOA and vigabatrin indeed increased the photosynthetic $\mathrm{Fv} / \mathrm{Fm}$ ratio, increased the chlorophyll level, and reduced the level of MDA in hybrid Liriodendron after $\mathrm{AlCl}_{3}$ exposure compared with the levels in the control plants (Fig. 7A, B). Consistent with this, L-allylglycine treatment exerted the opposite effects on these parameters (Fig. 7A, B).

Another parameter reflecting plant seedling tolerance to $\mathrm{AlCl}_{3}$ stress is the average relative net root growth (RNRG), which compares root length before and after $\mathrm{AlCl}_{3}$ treatment ${ }^{23}$. Again, we found that GABA, AOA, or vigabatrin treatment improved root tolerance to $\mathrm{AlCl}_{3}$ stress compared to that in control plants, while Lallylglycine reduced the tolerance (Fig. $7 \mathrm{C}$ ). These data show that GABA signaling acts to increase hybrid Liriodendron tolerance to $\mathrm{AlCl}_{3}$ by protecting it from the damaging effects of $\mathrm{AlCl}_{3}$ toxicity.

The hybrid Liriodendron leaf viability/photosynthetic capability was further characterized in response to $30 \mu \mathrm{M}$ $\mathrm{AlCl}_{3}$ and $30 \mu \mathrm{M} \mathrm{AlCl}$ supplemented with $10 \mathrm{mM}$ GABA. We found that the viability/photosynthetic capability of hybrid Liriodendron leaves subjected to $\mathrm{AlCl}_{3}+$
GABA after 7 days of treatment was better than that of the $\mathrm{AlCl}_{3}$ treatment group (Supplemental Fig. 3). Although the $\mathrm{Fv} / \mathrm{Fm}$ ratio decreased in the leaves treated with $\mathrm{AlCl}_{3}+\mathrm{GABA}$, it was still higher than that in the leaves treated with $\mathrm{AlCl}_{3} \cdot \mathrm{AlCl}_{3}+\mathrm{GABA}$ treatment also reduced MDA content, indicating that GABA relieved the membrane lipid oxidative damage. Furthermore, we found that the leaf transpiration rate and stomatal conductance levels, additional parameters that reflect photosynthetic activity, were also increased after $\mathrm{AlCl}_{3}+\mathrm{GABA}$ treatment compared with $\mathrm{AlCl}_{3}$ treatment. Thus, these data suggest that $\mathrm{GABA} \mathrm{AlCl}_{3}$ positively helps the leaves of hybrid Liriodendron resist aluminum stress.

\section{GABA signaling in response to Al stress may be a conserved pathway in higher plants}

Our results so far show that GABA enhances hybrid Liriodendron tolerance to $\mathrm{Al}$ stress, which is consistent with a previous study that showed that wheat species with tolerance to $\mathrm{Al}$ contained high levels of $\mathrm{GABA}^{23,24}$. In the plant kingdom, GABA has a wide range of regulatory functions in growth, development, abiotic stress responses, and defense ${ }^{38,39}$. Furthermore, GABA can function in different kingdoms because plants, animals, and fungi respond to $\mathrm{GABA}^{38-40}$. These results also suggest that 

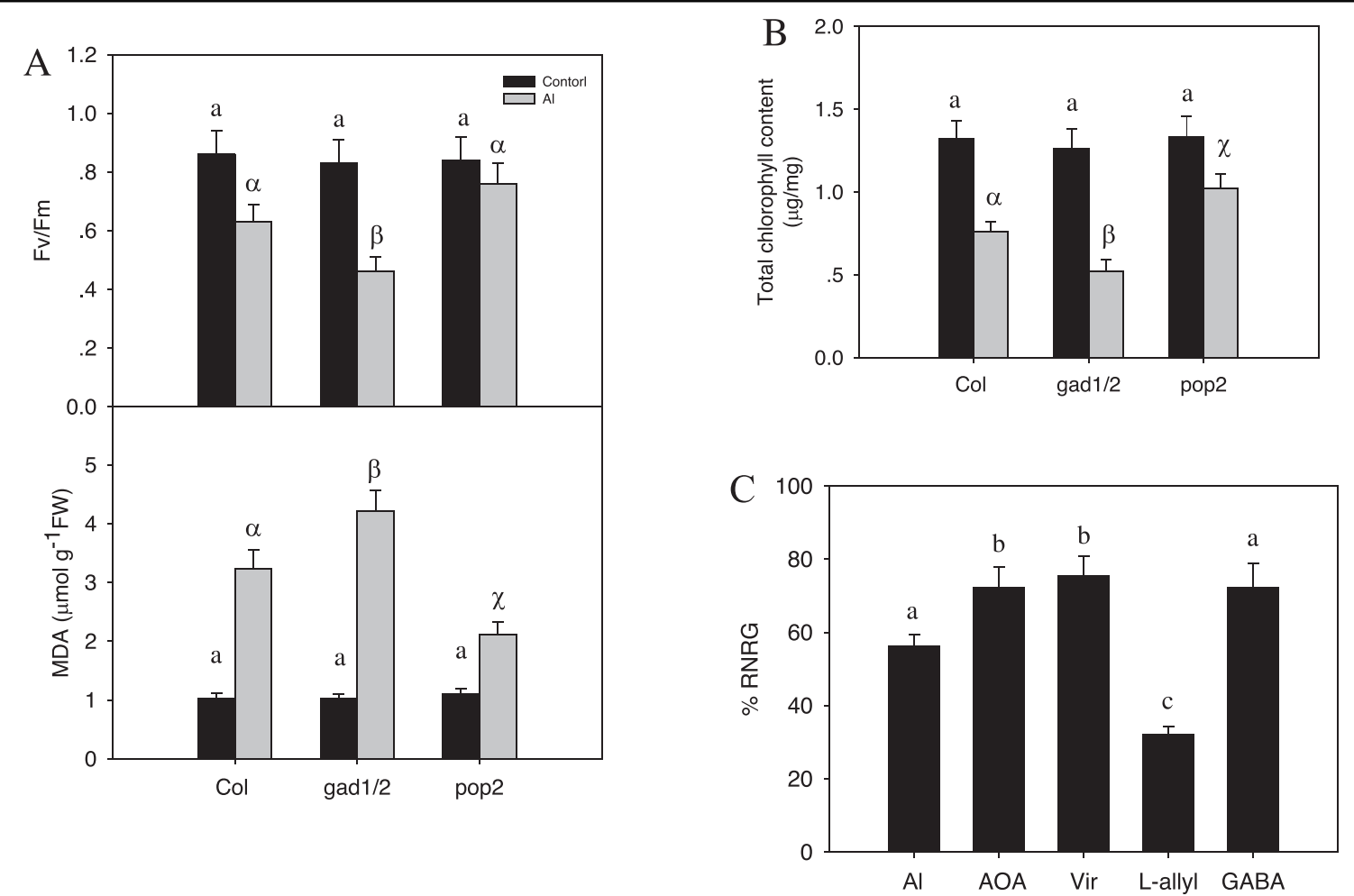

Fig. 8 The role of GABA in $\mathrm{AICl}_{3}$ stress signaling is conserved in Arabidopsis thaliana. The role of $\mathrm{GABA}$ in $\mathrm{AlCl}_{3}$ stress signaling is conserved in Arabidopsis thaliana. The experiment was performed in triplicate, and the data represent the mean \pm SD of three biological replicates. Different letters indicate statistically significant differences $(p<0.05)$ as determined by Tukey's multiple comparisons test. $\mathbf{A}, \mathbf{B}$ Effect of $\mathrm{AlCl}_{3}$ on leaf photosynthesisrelated Fv/Fm, MDA content, and total chlorophyll content in wild-type Col and in the gad1/2 and pop2 mutants. One-week-old seedlings were treated with $30 \mu \mathrm{M} \mathrm{AlCl}$ for 3 days, and the $\mathrm{Fv} / \mathrm{Fm}$ ratio and MDA content $(\mathbf{A})$, as well as the total chlorophyll content (B), were measured. C Effect of $\mathrm{AlCl}_{3}, \mathrm{GABA}$, and GABA biosynthesis inhibitor treatment on relative root elongation. One-week-old seedlings were treated with $30 \mu \mathrm{M} \mathrm{AICl}{ }_{3}$ or $30 \mu \mathrm{M}$ $\mathrm{AlCl}_{3}$ with different additional chemicals as described above for one week, and the relative root elongation was measured

GABA signaling, as an $\mathrm{Al}$ stress response, is a more widely conserved pathway in higher plants. To investigate this, we turned to the model system Arabidopsis. The Arabidopsis GABA-T-deficient pop2-1 mutant showed a high endogenous GABA content, while the Arabidopsis gad1/2 double mutant contained low levels of $\mathrm{GABA}^{22}$. We thus subjected wild-type Col, pop 2 , and gad1/2 double mutant seedlings to $\mathrm{AlCl}_{3}$ stress and then measured their physiological response. We first confirmed that in Arabidopsis, $\mathrm{Al}$ stress similarly reduced the $\mathrm{Fv} / \mathrm{Fm}$ ratio and total chlorophyll content and increased the MDA content compared to that in unstressed seedlings (Fig. 8A, B). Consistent with our hypothesis, the pop 2-1 mutant with high endogenous GABA content exhibited reduced $\mathrm{Al}$ toxicity, as it showed higher $\mathrm{Fv} / \mathrm{Fm}$ values and total chlorophyll content, lower MDA levels, and an increased RNRG (Fig. 8C). In contrast, the gad1/2 mutant with lower GABA levels showed lower Fv/Fm values and total chlorophyll content, higher MDA levels, and a lower RNRG. These findings indicate the critical role of GABA in enhancing plant tolerance to $\mathrm{Al}$ stress; furthermore, this function is possibly conserved across widely divergent plant species.

\section{Discussion}

Most woody plants grow on acidic soil and show tolerance to $\mathrm{Al}$ stress, but the mechanism underlying this tolerance remains unknown. To address this question, we used hybrid Liriodendron, a relative of $L$. chinense that has been sequenced and developed as a model system for woody plants in our lab, because of its ecological and economic value for wood cultivation ${ }^{25}$. We opted to use a proteomics approach to identify genetic pathways involved in $\mathrm{Al}$ stress resistance. We found that a large variety of pathways respond to Al toxicity and detected changes in auxin, BR, and GA biosynthesis pathways. We also detected changes in transcription factors such as WRKY and basic HLH, which are involved in $\mathrm{Al}$ stress tolerance in Arabidopsis; for example, Arabidopsis WRKY46 plays a role in $\mathrm{Al}$ tolerance ${ }^{16}$. Proteins involved in protein degradation and methylation status also regulate $\mathrm{Al}$ resistance in Arabidopsis ${ }^{41,42}$. Based on these 
findings, we propose that hybrid Liriodendron adopts a wide variety of strategies to control its $\mathrm{Al}$ stress response.

More specifically, we found that several metabolic enzymes involved in the synthesis of the signaling molecule GABA, including GAD (Lchi33118, Lchi05759, and succinate-semialdehyde dehydrogenase (Lchi21261), showed an increased expression level under $\mathrm{Al}$ stress. Accumulated evidence demonstrates that GABA has a physiological function in plant growth, development and defense responses ${ }^{19-21}$. Consistent with this finding, we found that $\mathrm{Al}$ stress indeed induced an increase in GAD1 activity and that GABA production by GAD1 was also increased after $\mathrm{Al}$ stress. Inhibiting the GAD1 enzyme activity by using the specific inhibitor L-allylglycine obviously reduced $\mathrm{Al}$ induced GABA generation, supporting the hypothesis that $\mathrm{Al}$-induced GABA biosynthesis depends on GAD activity. In plants, GABA is dynamically degraded by GABA-Tase VOA and Vir. We also treated hybrid Liriodendron seedlings with VOA or Vir and found that the treatment further enhanced Al-induced GABA biosynthesis by suppressing GABA-Tase activity and compromising GABA degradation. The essential role of the GABA shunt in preventing ROS generation and cell death during UV or heat stress has been reported. Here, our iTRAQ data showed that Al stress upregulated the protein levels of several antioxidant enzymes, including CAT and SOD. Rapid accumulation of ROS, mainly $\mathrm{H}_{2} \mathrm{O}_{2}$ and $\mathrm{O}^{2-}$, and an increase in antioxidant enzyme activity were observed after exposure to $\mathrm{Al}$ stress. Furthermore, we found that supplementation with GABA or enhancement of endogenous GABA levels by AOA or Vir enhanced Alinduced antioxidant enzyme activity and reduced ROS accumulation, while suppressing GAD1 enzyme activity by using L-allylglycine compromised GABA levels and reduced antioxidant enzyme activities, leading to increased ROS accumulation. A previous study showed that the GABA shunt was involved in ROS metabolism during UV or salt stress. Our finding here is in agreement with this finding and demonstrated that GABA efficiently increased antioxidant enzyme activities for scavenging ROS during $\mathrm{Al}$ stress. Our iTRAQ results also showed that $\mathrm{Al}$ stress induced the protein accumulation of P5CS, which is the key enzyme for proline biosynthesis. Proline also accumulated at high levels in plants under environmental stress ${ }^{43}$. Environmental stress induces the generation of proline to balance cellular osmotic pressure $^{33,34,43}$, and proline has been shown to perform multiple antioxidant functions ${ }^{44}$. Here, we found that $\mathrm{Al}$ stress induced the biosynthesis of proline. Additional GABA or GABA-Tase inhibitor treatment further increased Alinduced proline biosynthesis, while suppressing GABA biosynthesis by L-allylglycine also reduced Al-induced proline biosynthesis. These data suggest that GABA also controls Al-induced proline biosynthesis, which may be used for multiple antioxidant responses under Al stress. Unlike drought stress, proline, when accumulated at high levels, is believed to be not only an osmolyte but also a signaling molecule that provides defense against oxidative damage.

Secretion of organic acids, including malate and citrate, to chelate $\mathrm{Al}$ plays an essential role in plant tolerance to $\mathrm{Al}$ stress $^{4}$. ALMT facilitates malate efflux, while MATEs facilitate citrate efflux ${ }^{10}$. Our iTRAQ results demonstrated that $\mathrm{Al}$ stress triggered the upregulation of MATE1 and MATE2. RT-qPCR results also showed that $\mathrm{Al}$ stress increased the transcriptional level of $M A T E 1 / 2$, suggesting the possible role of MATE-mediated citrate in Al tolerance. Consistent with this finding, we found that $\mathrm{Al}$ stress indeed induced an increase in citrate in hybrid Liriodendron roots, and the citrate efflux capability also increased after $\mathrm{Al}$ stress. These results suggest that citrate efflux chelates $\mathrm{Al}$ enhance hybrid Liriodendron tolerance to $\mathrm{Al}$ stress. A previous study demonstrated that GABA regulates ALMT for malate efflux. Here, we also found that additional GABA, AOA, or Vir treatment increased the transcription of $M A T E 1 / 2$ and the efflux of citrate, which may explain why GABA signaling enhances hybrid Liriodendron tolerance to $\mathrm{Al}$ stress. In contrast, suppressing GABA biosynthesis by using L-allylglycine compromised $\mathrm{Al}$-induced transcription of $M A T E 1 / 2$ and decreased citrate efflux. These data further support the critical role of GABA signaling in promoting citrate efflux for $\mathrm{Al}$ tolerance. Moreover, we found that GABA signaling also enhanced $\mathrm{Al}$ induced malate efflux. In wheat roots, $\mathrm{Al}$-activated malate transport also facilitates GABA transport; thus, whether or how GABA signaling controls malate or citrate efflux through ALMT or MATE1/2 needs further investigation.

In conclusion, our proteomics approach using quantitative iTRAQ technology to analyze the differential expression of proteins in hybrid Liriodendron leaves subjected to $\mathrm{Al}$ stress found that hybrid Liriodendron likely adopts multiple strategies to enhance its $\mathrm{Al}$ stress tolerance: changes in metabolism, sugar and proline biosynthesis, differential transcription factor expression, cell autophagy and ubiquitin-dependent protein degradation to anion transport. Through further study, we revealed a novel role for the nonclassic amino acid GABA, which controls multiple aspects of the $\mathrm{Al}$ stress response in not only hybrid Liriodendron but also Arabidopsis. Therefore, our results help to further explain how plants combat $\mathrm{Al}$ toxicity, and these findings should aid in the broad application of gene engineering in hybrid Liriodendron and other plants to improve their Al tolerance.

\footnotetext{
Acknowledgements

This work was supported by the National Natural Science Foundation of China (32071784 and 31770715), Natural Science Foundation of Jiangsu Province (BK20181176), Qinglan project of Jiangsu province, Priority Academic Program Development of Jiangsu Higher Education Institutions.

\section{Author details}

${ }^{1}$ Key Laboratory of Forest Genetics \& Biotechnology of Ministry of Education of China, Co-Innovation Center for Sustainable Forestry in Southern China,
} 
Nanjing Forestry University, Nanjing 210037, China. ${ }^{2}$ Suzhou Polytechnic Institute of Agriculture, Suzhou 215008, China. ${ }^{3}$ Shanghai Key Laboratory of Bio-Energy Crops, School of Life Sciences, Shanghai University, Shanghai 200444, China. ${ }^{4}$ College of Forestry, Nanjing Forestry University, Nanjing 210037, China. ${ }^{5}$ College of Biology and the Environment, Nanjing Forestry University, Nanjing 210037, China

\section{Conflict of interest}

The authors declare no competing interests.

Supplementary information The online version contains supplementary material available at https://doi.org/10.1038/s41438-021-00517-y.

Received: 20 July 2020 Revised: 1 February 2021 Accepted: 6 February 2021 Published online: 01 April 2021

\section{References}

1. Kochian, L. V., Pineros, M. A. \& Hoekenga, O. A. The physiology, genetics and molecular biology of plant aluminum resistance and toxicity. Plant Soil $\mathbf{2 7 4}$ 175-195 (2005).

2. Horst, W. J., Wang, Y. \& Eticha, D. The role of the root apoplast in aluminiuminduced inhibition of root elongation and in aluminium resistance of plants: a review. Ann. Bot. 106, 185-197 (2010).

3. Sade, $\mathrm{H}$. et al. Toxicity and tolerance of aluminum in plants: tailoring plants to suit to acid soils. Biometals 29, 187-210 (2016).

4. Kochian, L. V., Pineros, M. A., Liu, J. \& Magalhaes, J. V. Plant adaptation to acid soils: the molecular basis for crop aluminum resistance. Annu. Rev. Plant Biol. 66, 571-598 (2015).

5. Uexküll, H. R. V. \& Mutert, E. Global extent, development and economic impact of acid soils. Plant Soil 171, 1-15 (1995).

6. Matsumoto, $\mathrm{H}$. Cell biology of aluminum toxicity and tolerance in higher plants. Int. Rev. Cytol. 200, 1-46 (2000).

7. Ahonen-Jonnarth, U., Goransson, A. \& Finlay, R. D. Growth and nutrient uptake of ectomycorrhizal Pinus sylvestris seedlings in a natural substrate treated with elevated Al concentrations. Tree Physiol. 23, 157-167 (2003).

8. Grisel, N. et al. Transcriptome responses to aluminum stress in roots of aspen (Populus tremula). Bmc Plant Biol. 10, 185 https://doi.org/10.1186/ 1471-2229-10-185 (2010).

9. Sasaki, T. et al. A wheat gene encoding an aluminum-activated malate transporter. Plant J.: Cell Mol. Biol. 37, 645-653 (2004).

10. Hoekenga, O. A. et al. AtALMT1, which encodes a malate transporter, is identified as one of several genes critical for aluminum tolerance in Arabidopsis. Proc. Natl Acad. Sci. USA 103, 9738-9743 (2006).

11. Ligaba, A., Katsuhara, M., Ryan, P. R., Shibasaka, M. \& Matsumoto, H. The BnALMT1 and BnALMT2 genes from rape encode aluminum-activated malate transporters that enhance the aluminum resistance of plant cells. Plant Physiol. 142, 1294-1303 (2006).

12. Magalhaes, J. V. et al. A gene in the multidrug and toxic compound extrusion (MATE) family confers aluminum tolerance in sorghum. Nat. Genet. 39, 1156-1161 (2007).

13. Upadhyay, N. et al. The multitasking abilities of MATE transporters in plants. J. Exp. Botany, https://doi.org/10.1093/jxb/erz246 (2019).

14. luchi, S. et al. Zinc finger protein STOP1 is critical for proton tolerance in Arabidopsis and coregulates a key gene in aluminum tolerance. Proc. Natl Acad. Sci. USA 104, 9900-9905 (2007).

15. Tsutsui, T., Yamaji, N. \& Feng Ma, J. Identification of a cis-acting element of ART1, a C2H2-type zinc-finger transcription factor for aluminum tolerance in rice. Plant Physiol. 156, 925-931 (2011).

16. Ding, Z. J., Yan, J. Y., Xu, X. Y., Li, G. X. \& Zheng, S. J. WRKY46 functions as a transcriptional repressor of ALMT1, regulating aluminum-induced malate secretion in Arabidopsis. Plant J. 76, 825-835 (2013).

17. Wang, J. P., Raman, H., Zhang, G. P., Mendham, N. \& Zhou, M. X. Aluminium tolerance in barley (Hordeum vulgare L.): physiological mechanisms, genetics and screening methods. J. Zhejiang Univ. Sci. B 7, 769-787 (2006).

18. Taylor, G. J. et al. Direct measurement of aluminum uptake and distribution in single cells of Chara corallina. Plant Physiol. 123, 987-996 (2000).
19. Shelp, B. J., Bown, A. W. \& McLean, M. D. Metabolism and functions of gammaaminobutyric acid. Trends Plant Sci. 4, 446-452 (1999).

20. Kinnersley, A. M. \& Turano, F. J. Gamma aminobutyric acid (GABA) and plant responses to stress. Crit. Rev. Plant Sci. 19, 479-509 (2000).

21. Bouche, N. \& Fromm, H. GABA in plants: just a metabolite? Trends Plant Sci. $\mathbf{9}$ 110-115 (2004)

22. Renault, $H$. et al. The Arabidopsis pop2-1 mutant reveals the involvement of GABA transaminase in salt stress tolerance. Bmc Plant Biol. 10, 20 (2010).

23. Ramesh, S. A. et al. GABA signalling modulates plant growth by directly regulating the activity of plant-specific anion transporters. Nat. Commun. $\mathbf{6}$ 7879 (2015).

24. Ramesh, S. A. et al. Aluminum-activated malate transporters can facilitate GABA transport([OPEN]). Plant Cell 30, 1147-1164 (2018).

25. Chen, J. et al. Liriodendron genome sheds light on angiosperm phylogeny and species-pair differentiation. Nat. Plants 5, 18-25 (2019).

26. Huo, A. et al. Establishment of transient gene expression systems in protoplasts from Liriodendron hybrid mesophyll cells. PLoS ONE 12, e0172475 (2017).

27. Bai, X. G. et al. Deciphering the protective role of nitric oxide against salt stress at the physiological and proteomic levels in maize. J. Proteome Res. 10, 4349-4364 (2011)

28. Hu, X. Y., Neill, S. J., Cai, W. M. \& Tang, Z. C. Induction of defence gene expression by oligogalacturonic acid requires increases in both cytosolic calcium and hydrogen peroxide in Arabidopsis thaliana. Cell Res. 14, 234-240 (2004)

29. Elstner, E. F. \& Heupel, A. Inhibition of nitrite formation from hydroxylammoniumchloride: a simple assay for superoxide dismutase. Anal. Biochem. 70, 616-620 (1976).

30. Zhang, G. J. \& Bown, A. W. The rapid determination of gamma-aminobutyric acid. Phytochemistry 44, 1007-1009 (1997)

31. Cheng, T. L. et al. Quantitative proteomics analysis reveals that Snitrosoglutathione reductase (GSNOR) and nitric oxide signaling enhance poplar defense against chilling stress. Planta 242, 1361-1390 (2015).

32. Bouche, N., Fait, A., Bouchez, D., Moller, S. G. \& Fromm, H. Mitochondrial succinic-semialdehyde dehydrogenase of the gamma-aminobutyrate shunt is required to restrict levels of reactive oxygen intermediates in plants. Proc. Natl Acad. Sci. USA 100, 6843-6848 (2003).

33. Szabados, L. \& Savoure, A. Proline: a multifunctional amino acid. Trends Plant Sci. 15, 89-97 (2010).

34. Verslues, P. E. \& Sharma, S. Proline metabolism and its implications for plantenvironment interaction. Arabidopsis Book 8, e0140 (2010).

35. Liu, J., Magalhaes, J. V., Shaff, J. \& Kochian, L. V. Aluminum-activated citrate and malate transporters from the MATE and ALMT families function independently to confer Arabidopsis aluminum tolerance. Plant J.: cell Mol. Biol. 57, 389-399 (2009).

36. Zimmerli, L., Jakab, G., Métraux, J.-P. \& Mauch-Mani, B. Potentiation of pathogen-specific defense mechanisms in Arabidopsis by $\beta$-aminobutyric acid. Proc. Natl Acad. Sci. 97, 12920 (2000).

37. Cohen, Y. The BABA story of induced resistance. Phytoparasitica 29, 375 (2001).

38. Seifikalhor, M., Aliniaeifard, S., Hassani, B., Niknam, V. \& Lastochkina, O. Diverse role of $\mathrm{Y}$-aminobutyric acid in dynamic plant cell responses. Plant Cell Rep. 38, 847-867 (2019)

39. Ramesh, S. A., Tyerman, S. D., Gilliham, M. \& Xu, B. Y-Aminobutyric acid (GABA) signalling in plants. Cell. Mol. Life Sci. 74, 1577-1603 (2017).

40. Shelp, B. J., Bown, A. W. \& Faure, D. Extracellular $\gamma$-aminobutyrate mediates communication between plants and other organisms. Plant Physiol. 142, 1350 (2006).

41. Geng, X. et al. LEUNIG_HOMOLOG transcriptional co-repressor mediates aluminium sensitivity through PECTIN METHYLESTERASE46-modulated root cell wall pectin methylesterification in Arabidopsis. Plant J.: Cell Mol. Biol. 90, 491-504 (2017).

42. Zhang, Y. et al. F-box protein RAE1 regulates the stability of the aluminumresistance transcription factor STOP1 in Arabidopsis. Proc. Natl Acad. Sci. USA 116, 319-327 (2019).

43. Khan, N., Bano, A., Rahman, M. A., Rathinasabapathi, B. \& Babar, M. A. UPLCHRMS-based untargeted metabolic profiling reveals changes in chickpea (Cicer arietinum) metabolome following long-term drought stress. Plant, Cell Environ. 42, 115-132 (2019).

44. Bose, J., Rodrigo-Moreno, A. \& Shabala, S. ROS homeostasis in halophytes in the context of salinity stress tolerance. J. Exp. Bot. 65, 1241-1257 (2014). 